\title{
Endotracheal Intubation Training and Skill Maintenance for Respiratory Therapists
}

\author{
Andrew G Miller RRT-ACCS RRT-NPS
}

\begin{abstract}
BACKGROUND: Endotracheal intubation is commonly performed outside the operating room (OR). Although respiratory therapists (RTs) performing endotracheal intubation is a well-established practice, the optimum way for RTs to be trained and maintain their skills is unspecified. The purpose of this study was to describe training methods and skills maintenance methods and to identify barriers that prevent RTs from intubating in some institutions. METHODS: A survey instrument was developed by the author. The survey was posted on the AARConnect online social media platform management section in March of 2015 after approval from our institutional review board and approval from the American Association for Respiratory Care board of directors. Respondents from institutions where RTs intubate received questions about RT training and skill maintenance, whereas the other respondents received questions about barriers to RTs performing endotracheal intubation. Both groups answered questions about attitudes about endotracheal intubation practice. RESULTS: There were $\mathbf{7 4}$ respondents who completed the survey. Half $(50 \%)$ of the respondents were from institutions where RTs performed endotracheal intubation. These institutions were larger in bed capacity and had more adult ICU beds. Other demographic data were similar. The most common training methods identified were simulation training (86\%), supervised intubations $(84 \%)$, and classroom training $(65 \%)$. Classroom training lasted a mean of $4.3 \mathrm{~h}$ with a range of $1-16 \mathrm{~h}$. The majority $(91 \%)$ were required to complete 10 or fewer supervised endotracheal intubations before competency validation. Skill recertification was automatic if a minimum number of endotracheal intubations were performed annually in $78 \%$ of centers, and $11 \%$ required a written test or classroom training annually. The primary barrier cited for RTs not intubating was lack of need. CONCLUSIONS: Endotracheal intubation training for RTs varied among those surveyed. Simulation training and supervised endotracheal intubations were the most common training methods. Endotracheal intubation recertification methods were also wide-ranging, with most RTs being recertified if completing a minimum number of endotracheal intubations. Key words: intubation; intubation training; respiratory care; respiratory therapist. [Respir Care 2017;62(2):156-162. (o 2017 Daedalus Enterprises]
\end{abstract}

\section{Introduction}

Endotracheal intubation is commonly performed outside the operating room (OR) to enable invasive mechanical ventilation, protect the patient's airway, facilitate patient trans-

The author is affiliated with Respiratory Care Services, Duke University Medical Center, Durham, North Carolina.

Supplementary material related to this paper is available at http:// www.rcjournal.com.

Mr Miller has disclosed no conflicts of interest.

Correspondence: Andrew G Miller RRT-ACCS RRT-NPS, Duke University Medical Center, Respiratory Care Services, PO Box 3911, 2301 Erwin Road, Durham, NC 27710. E-mail: Andrew.g.miller@duke.edu.

DOI: $10.4187 /$ respcare.05037 port or for other clinical objectives. Intubation in the OR is usually performed under controlled circumstances that include a complete airway assessment and a review of patient history. In contrast, intubation performed outside the OR is often done emergently, without time to obtain an adequate airway assessment, in patients with poor cardiovascular reserve, often in geographically challenging surroundings and by personnel with less training than anesthesiologists. Many intubations outside of the OR are done during cardiac arrests or other emergencies outside of the ICU. These and other factors contribute to intubation outside the OR carrying an increased risk of adverse events, such as esophageal intubation, hypoxemia, cardiovascular collapse, and cardiac arrest. ${ }^{1}$ The risk of one or more adverse events increases when inexperienced or inadequately trained personnel attempt intubation. ${ }^{2,3}$ 
In many institutions, respiratory therapists (RTs) provide intubation in emergencies or elective procedures. The efficacy of RTs performing intubation is well-established, with success rates comparable with those of physicians. ${ }^{4-7}$ The optimal way for RTs to be trained to perform intubation is unclear, since different methods have been described in the peer-reviewed literature. Intubation skill maintenance is also poorly described in the literature, for RTs and other healthcare personnel. The purpose of this study was to explore the methods currently being used to train RTs to perform intubation, to explore how their skills are maintained and evaluated, and to identify, through the use of a survey instrument, barriers to RTs intubating in institutions where RTs do not intubate.

\section{Methods}

Following a literature review, a survey instrument (Appendix $\mathrm{A}$; see the supplementary materials at http:// www.rcjournal.com) was developed by the author and sent to several fellow RTs with expertise in survey-based research and advanced airway management for feedback. Changes were made to the survey based on their feedback as well as feedback from the Duke University Medical Center Respiratory Care Services research committee. The survey was posted on the AARConnect online social media platform management section in March of 2015 after approval by the Duke University institutional review board and approval from the AARC board of directors. Respondents were limited to department directors and managers to reduce the risk of institutional bias. Reminders to fill out the survey were posted weekly for 2 weeks after the initial posting. It was not possible to calculate a response rate because the number of directors/managers who are members of the AARConnect management section is unknown.

Following questions about hospital demographics, the survey split based on whether RTs intubated at the institution. In institutions where RTs intubate, questions were asked about staffing, qualifications, training, skill maintenance, and attitudes about their intubation practice. For institutions where RTs do not intubate, questions were asked about barriers to RTs providing intubation and attitudes about their intubation practice. A $P$ value of $<.05$ was considered to be statistically significant. The Fisher exact test and unpaired $t$ test were performed for categorical data and continuous data, respectively. Ninety-five percent CIs were calculated using the Wald method due to the low number of responses, to underscore that the results lack precision. ${ }^{8}$

\section{Results}

There were a total of 74 respondents, and $50 \%$ were from institutions where RTs perform intubation. Only complete responses were included in the final data analysis. Results for demographic data are summarized in Table 1.

\section{QUICK LOOK}

\section{Current knowledge}

Endotracheal intubation occurs frequently outside of the operating room for a variety of reasons. Respiratory therapists perform endotracheal intubation in many hospitals. Current literature supports this practice, although different training methodologies and skill maintenance practices have been described.

\section{What this paper contributes to our knowledge}

There was no consensus on how RTs were trained to perform endotracheal intubation. Simulation training and supervised intubations were the most common training methods. Skill recertification also varied, with most RTs being recertified if completing a minimum number of intubations.

Twenty-one respondents $(57 \%, 95 \%$ CI $0.41-0.71)$ engaged in quality assurance monitoring. The most common data monitored were: success rate $(90 \%, 95 \%$ CI $0.70-$ 0.99), number of attempts $(86 \%, 95 \%$ CI $0.65-0.95)$, complications $(71 \%, 95 \%$ CI $0.50-0.86)$, and equipment used (43\%, 95\% CI $0.24-0.63)$.

Results for staff selection, prior experience, credentials, and life support training requirements are summarized in Figure 1. Results for training methods and topics covered during classroom training are summarized in Figure 2.

Classroom education ranged from 1 to $16 \mathrm{~h}$, with a mean of $4.3 \pm 3.4 \mathrm{~h}$. Before allowing intubation on actual patients, $92 \%$ (95\% CI $0.78-0.98$ ) required hands-on simulation training, $51 \%$ (95\% CI $0.36-0.67)$ required classroom training, and $38 \%$ (95\% CI $0.24-0.54)$ required a passing score on a written exam.

Twenty-seven respondents answered who taught their classroom education, with $85 \%$ (95\% CI $0.67-0.95$ ) taught by RTs, 33\% (0.19-0.52) by anesthesiologists, $15 \%$ (95\% CI $0.05-0.33$ ) by critical care physicians, and 7\% (95\% CI 0.010.24 ) by emergency physicians. Thirty-four respondents answered questions about supervised intubations, with $62 \%$ (95\% CI 0.45-0.76) requiring between 1 and 5, 29\% (95\% CI $0.17-0.46$ ) requiring between 6 and 10, and $9 \%$ (95\% CI $0.02-0.24$ ) requiring $>10$. One respondent indicated that their staff was required to successfully intubate in a simulation session 20 times before intubating patients. Thirtyseven respondents answered where supervised intubations were performed as part of their intubation training: $57 \%$ (95\% CI 0.41-0.71) were performed in the OR, $49 \%$ (95\% CI $0.33-0.64)$ as elective intubations in the ICU or emergency department, and 35\% (95\% CI 0.22-0.51) in emergencies outside the ICU, and $11 \%$ of respondents (95\% CI $0.04-$ 0.25 ) indicated that supervised intubations were not part of their program. 
ENDOTRACHEAL INTUBATION TRAINING FOR RTS

Table 1. Respondent's Demographics

\begin{tabular}{|c|c|c|c|}
\hline & Performed Endotracheal Intubation & Did Not Perform Endotracheal Intubation & $P$ \\
\hline Respondents, $n(\%)$ & 37 & 37 & NA \\
\hline Academic & $8(22)$ & $8(22)$ & $>.99$ \\
\hline Community & $26(70)$ & $27(73)$ & $>.99$ \\
\hline Tertiary & $6(16)$ & $3(8)$ & .48 \\
\hline Level 1 trauma center & $6(16)$ & $1(3)$ & .11 \\
\hline Total number of beds* & $431 \pm 397$ & $257 \pm 206$ & .02 \\
\hline RTs on staff, mean $\pm \mathrm{SD}$ & $61 \pm 59$ & $40 \pm 40$ & .08 \\
\hline Adult ICU, $n(\%)$ & $35(95)$ & $36(97)$ & $>.99$ \\
\hline Adult ICU beds, mean $\pm \mathrm{SD}$ & $58 \pm 69$ & $26 \pm 28$ & .01 \\
\hline $\mathrm{PICU}, n(\%)$ & 7 (19) & $5(14)$ & .75 \\
\hline PICU beds, mean $\pm \mathrm{SD}$ & $20 \pm 15$ & $27 \pm 25$ & .15 \\
\hline NICU, $n(\%)$ & $23(62)$ & $17(46)$ & .24 \\
\hline $\mathrm{NICU}$ beds, mean $\pm \mathrm{SD}$ & $35 \pm 26$ & $25 \pm 19$ & .063 \\
\hline \multicolumn{4}{|c|}{$\begin{array}{l}\text { *One response censored for unclear information. } \\
\text { NA }=\text { not applicable } \\
\text { RT }=\text { respiratory therapist } \\
\text { PICU }=\text { pediatric ICU } \\
\text { NICU = neonatal ICU }\end{array}$} \\
\hline
\end{tabular}

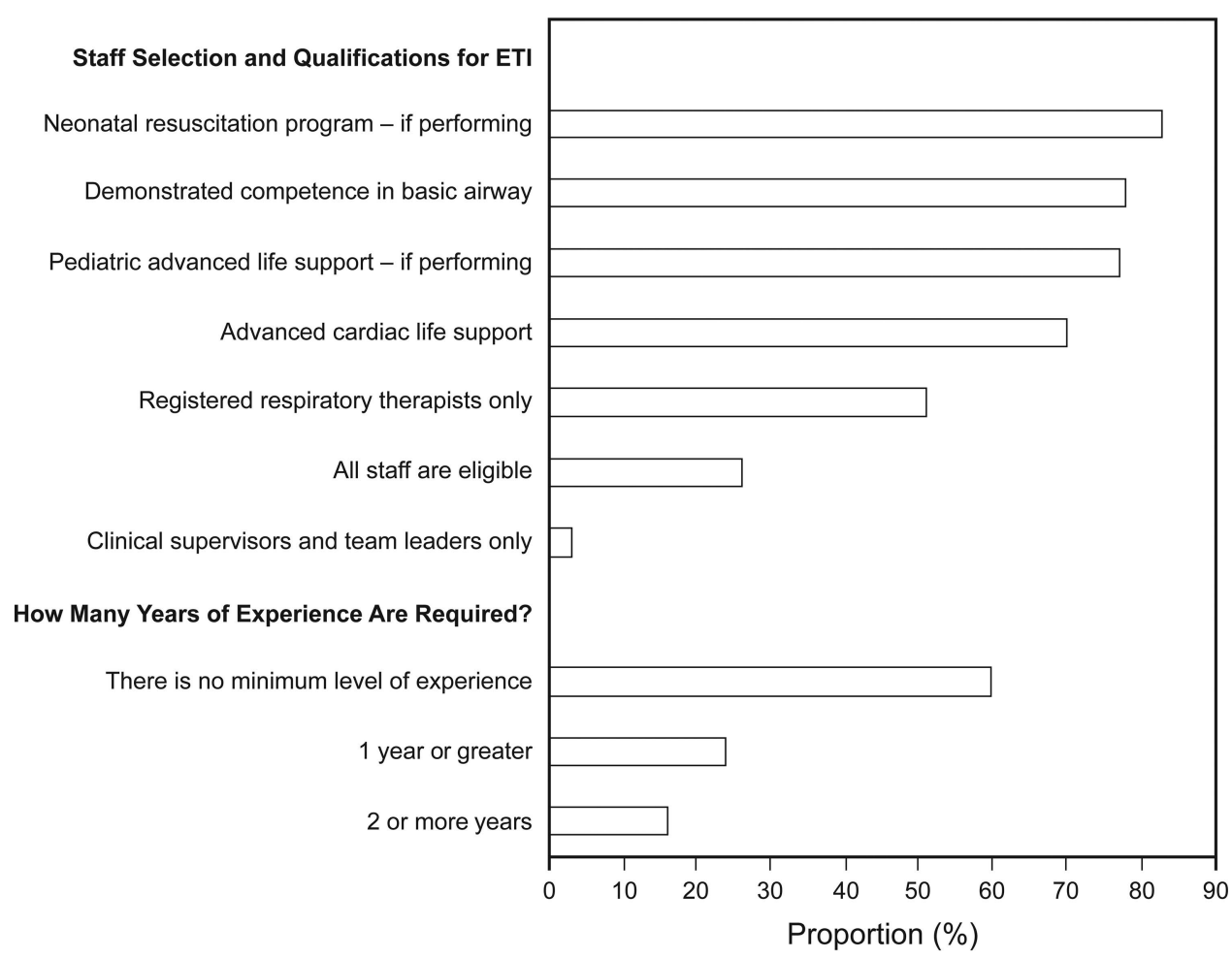

Fig. 1. Summary of staff selection, staff qualifications, and experience before endotracheal intubation (ETI) training.

RTs were automatically recertified after completing a minimum number of intubations annually in 78\% (95\% CI $0.63-$ 0.89 ) of centers, $59 \%$ (95\% CI $0.43-0.74$ ) required observed competency in a clinical setting, 32\% (95\% CI 0.20-0.49) required observed competency in a simulation setting, $24 \%$ (95\% CI 0.13-0.40) required observed competency in an OR setting, $11 \%$ (95\% CI $0.04-0.25)$ required a written test, $11 \%$ (95\% CI $0.04-0.25$ ) required classroom retraining, and $3 \%(95 \% \mathrm{CI}<0.001-0.15)$ did not require any recertification. For RTs who did not meet their standard for recertification, $69 \%$ (95\% CI $0.54-0.83$ ) were required to complete the entire education process again. 


\section{ENDOTRACHEAL INTUBATION TRAINING FOR RTs}

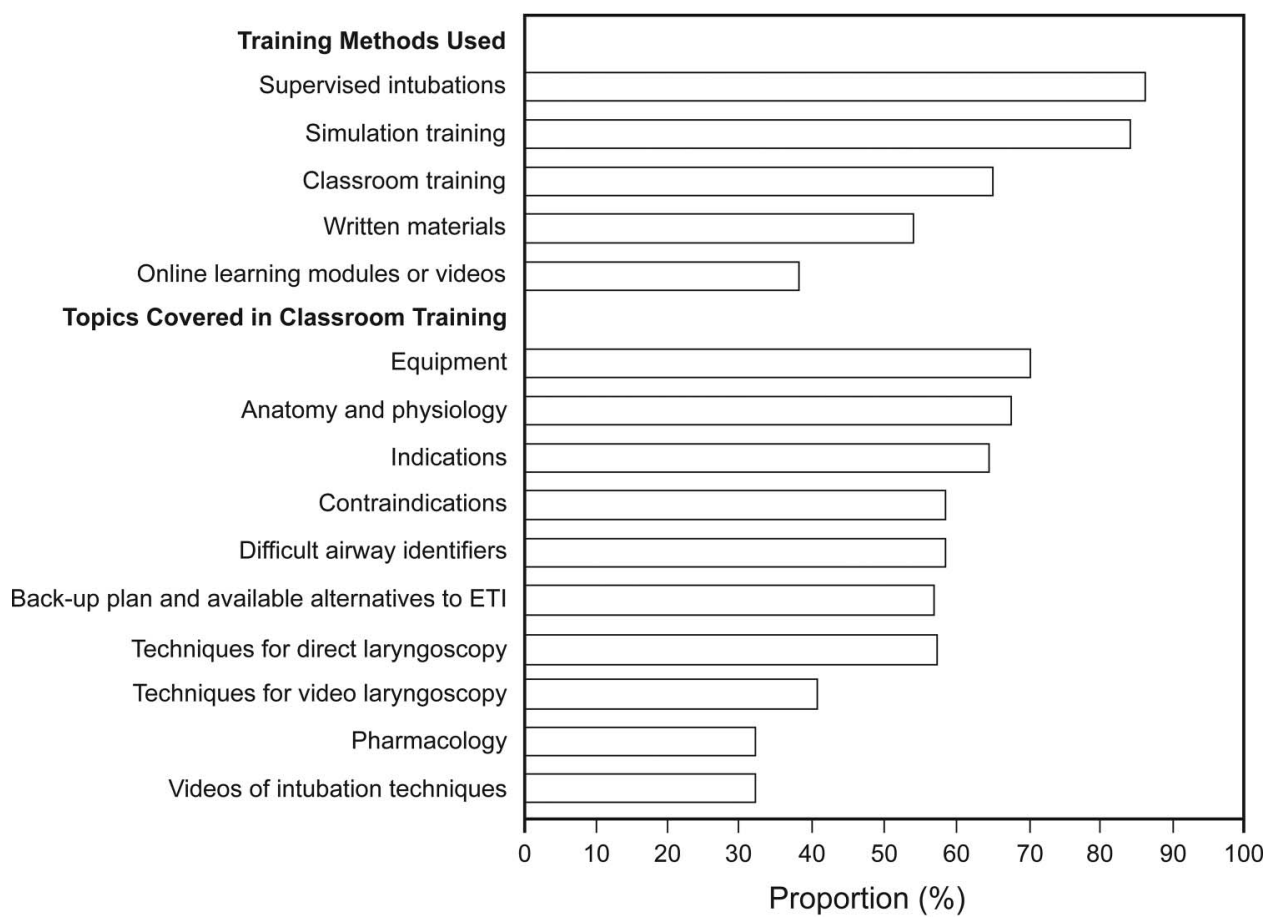

Fig. 2. Summary of the training methods and classroom training topics for endotracheal intubation (ETI).

Table 2. Respondent Beliefs About Respiratory Therapist's Intubation Practice

\begin{tabular}{|c|c|c|c|c|c|c|c|}
\hline \multirow{2}{*}{$\begin{array}{c}\text { To What Degree Do You Personally Believe } \\
\text { With the Following Statements? }\end{array}$} & \multicolumn{3}{|c|}{ RTs Perform Endotracheal Intubation } & \multicolumn{3}{|c|}{$\begin{array}{l}\text { RTs Do Not Perform Endotracheal } \\
\text { Intubation }\end{array}$} & \multirow[t]{2}{*}{$P$} \\
\hline & Agreed & Neutral & Disagreed & Agreed & Neutral & Disagreed & \\
\hline RTs can safely intubate patients & 92 & 0 & 8 & 89 & 8 & 3 & .23 \\
\hline $\begin{array}{l}\text { RTs should be primary providers of } \\
\text { endotracheal intubation }\end{array}$ & 76 & 16 & 8 & 42 & 50 & 8 & .004 \\
\hline $\begin{array}{l}\text { I am satisfied with my institution's current program } \\
\text { for providing endotracheal intubation program }\end{array}$ & 60 & 16 & 24 & 50 & 33 & 17 & .21 \\
\hline $\begin{array}{l}\text { State licensure should require advanced airway } \\
\text { competence evaluation (similar to the } \\
\text { requirements for ECMO specialists) for all } \\
\text { RTs who perform endotracheal intubation }\end{array}$ & 27 & 30 & 43 & 53 & 24 & 24 & .07 \\
\hline Our RTs are well-trained to intubate & 78 & 11 & 11 & NA & NA & NA & NA \\
\hline $\begin{array}{l}\text { Our program adequately evaluates each RT's } \\
\text { competence each year }\end{array}$ & 62 & 22 & 16 & NA & NA & NA & NA \\
\hline \multicolumn{8}{|c|}{$\begin{array}{l}\text { Results are percentages. } P \text { values were calculated using the Fisher exact test. } \\
\text { RT }=\text { respiratory therapist } \\
\text { ECMO = extracorporeal membrane oxygenation } \\
\text { NA }=\text { not applicable }\end{array}$} \\
\hline
\end{tabular}

Attitudes about individual institutions' intubation programs were measured using a standard Likert scale (strongly agree, agree, neither agree nor disagree, disagree, strongly disagree, and not applicable). Four questions were posed to all respondents, whereas 2 were posed to respondents from institutions where RTs performed intubation. Respondents from institutions where RTs perform intubation were more likely to agree that RTs should be primary providers of intubation (76\% vs $42 \%, P=.004)$. There were no differences for the other questions. Results are summarized in Table 2 and Figure 3.

The majority of respondents from institutions where RTs do not intubate, $58 \%$ (95\% CI 0.42-0.73) indicated that they would like to provide intubation services. Thirty-four respondents answered questions about barriers to RTs performing intubation. Results are summarized in Figure 4. 


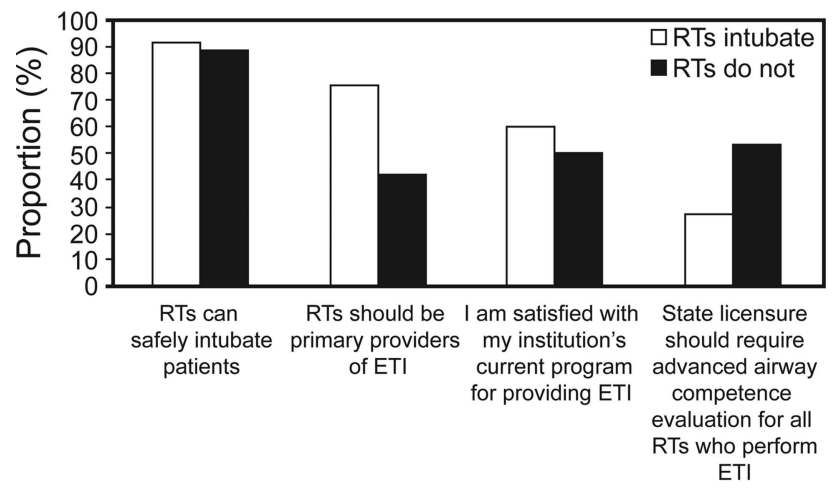

Fig. 3. Comparison of these who personally agree with statements about respiratory therapists' (RTs) endotracheal intubation (ETI) practice.

Other reasons cited for RTs not performing intubation were: competition from multiple disciplines, the presence of a teaching facility where resident physicians intubate, implementation of $24-\mathrm{h} / \mathrm{d}$ anesthesia coverage obviating the need for RTs to intubate, the fact that it is a lowvolume/high-risk procedure, the availability at all times of non-specified physicians, competition from family practice residents, competition from nurse anesthetists undergoing training, lack of support from anesthesia providers for RTs intubating, no RT staff at night, prior litigation resulting from a patient's death, lack of opportunities, and competition from residents.

\section{Discussion}

Due to the low number of responses, self-selection of respondents, potential self-reporting bias, and inability to calculate a response rate, the results of this survey should be interpreted cautiously. It does provide exploratory data opening a window into RT intubation training practices. The optimal way to train RTs to perform intubation is unclear, and as expected, there was significant variation in the training methods, skill maintenance, and recertification requirements among the respiratory therapy department directors/managers surveyed. The lack of consensus on intubation training also extends to critical care fellowship programs. ${ }^{9}$

There is currently a lack of peer-reviewed articles specifically evaluating intubation training of RTs. In the largest series published to date, Thalman et $\mathrm{al}^{6}$ described a training program that included $8 \mathrm{~h}$ of formalized instruction, which included intubation techniques, anatomy and physiology, pharmacology, and medico-legal issues. After passing written and simulation exams, RTs received competency validation after successfully intubating 10 patients within $1 \mathrm{y}$. Skill maintenance was assumed due to the large volume of procedures performed annually. ${ }^{6}$ Zyla and Carlson $^{7}$ described a didactic training program covering anatomy, medication, complications, and contraindications to both oral and nasal intubations was followed by an examination and simulation training before performing intubation in the OR. After completing 15 intubations, RTs received competency validation to perform intubation outside the OR. Skill maintenance for their RTs included an annual written test and a minimum of 15 intubations every $2 \mathrm{y}$. Importantly, some of their staff did not receive enough opportunities to meet these requirements. ${ }^{7}$ Noblett and Meibalane ${ }^{5}$ described their program in their NICU. Registered respiratory therapists (RRTs) were trained to perform intubation by a respiratory NICU supervisor. Each therapist was observed performing 3 successful intubations before being receiving competency to intubate unsupervised. Didactic training, simulation, or a written test were not described as training methods. ${ }^{5}$ Adams et $\mathrm{al}^{4}$ described RTs intubating as part of a transport team, RTs received mannequin training and a written examination only. Recertification methods were not described. ${ }^{4}$ None of these studies were designed to specifically examine RT training or skill maintenance.

In this survey, there was no consensus on staff selection for intubation training. Most respondents required advanced lifesupport classes, a demonstrated competence in basic airway management, and passing of the RRT exam before intubation training. Surprisingly, no respondents required a bachelor's degree or advanced credential (ACCS [adult critical care specialty] or NPS [neonatal/pediatric specialty]). The majority did not have a minimum level of experience before being eligible for intubation training. Unfortunately, studies comparing intubation success based on experience level, credentials, or education level have not been performed.

The most common training methods were supervised intubations, simulation, and classroom training. The number of supervised intubations required varied; the majority required between 1 and 5 intubations. The specific number of intubations needed to acquire competence for RTs has not been reported to date; however, a study of anesthesia residents found that a $90 \%$ success rate was achieved after completing 26-50 intubations, but their success rate did not exceed 95\% until after 150 successful intubations. ${ }^{10}$ Requiring 1-5 intubations for initial certification may not be adequate; however, supplemental high-fidelity simulation training may help to reduce the number of intubations necessary to develop and maintain intubation skills. Establishing the learning curve for RTs is an important area of future study.

The vast majority of respondents used simulation training. Simulation training is known to significantly improve advanced airway management skills when compared with no intervention. ${ }^{11} \mathrm{~A}$ meta-analysis found that OR training following simulation-based training did not confer additional benefit when compared with simulation training alone. It is important to note that none of the included studies included RTs. Further evidence is needed before simulation-based training can replace actual patient interaction for intubation training. Mosier et al recently evaluated the effect using an inten- 


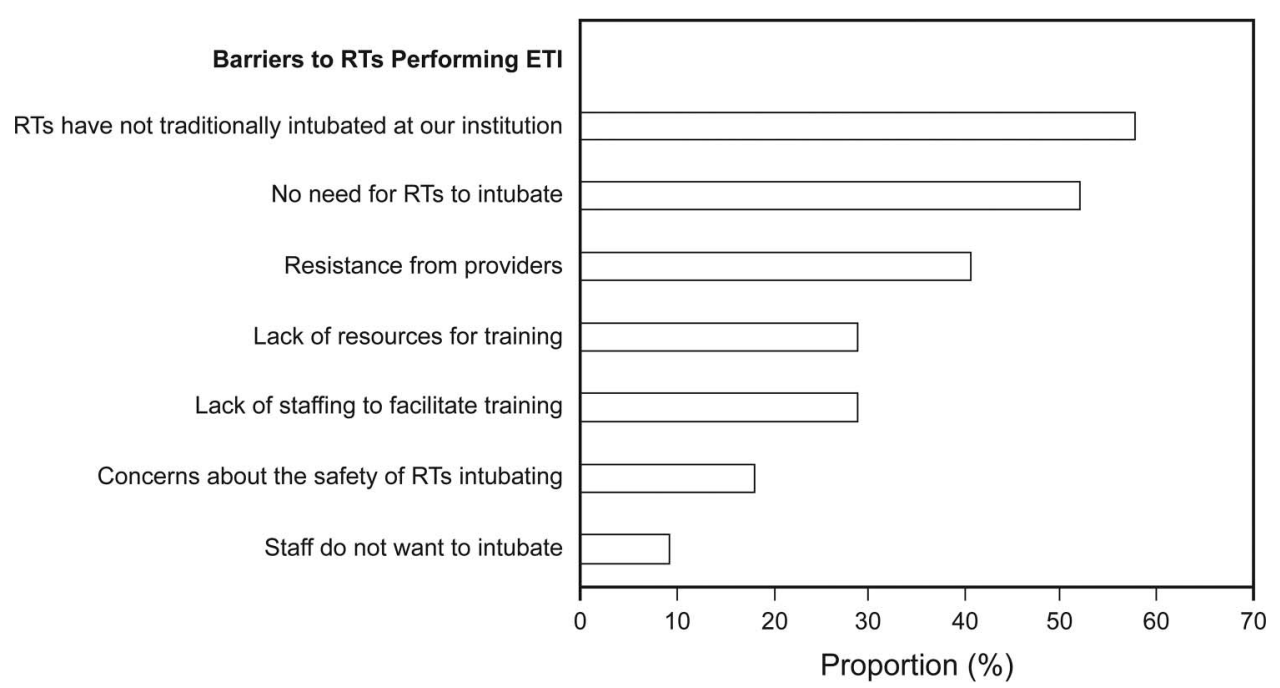

Fig. 4. Summary of the most common barriers to respiratory therapists (RTs) performing endotracheal intubations (ETI), as cited by respondents.

sive simulation-based program for their critical care fellows on airway management in their ICUs. The training included didactic training and simulation-based training performed over 11 months and included twice monthly sessions in small groups taught by advanced airway providers. They found an increase in first attempt success rate and a decrease in complications after the implementation of the program. ${ }^{12} \mathrm{~A}$ similar program could be implemented by respiratory care departments to reduce complications and improve patient safety during RT intubation attempts.

Classroom education was taught primarily by RT supervisors, educators, or selected staff members. The topics covered during classroom training varied (Fig. 2). Surprisingly, pharmacology and the use of video laryngoscopy were only included by a minority of respondents. A knowledge of pharmacology is necessary to a successful intubation program, and RTs should be trained on the use of video laryngoscopy because evidence suggests that video laryngoscopy improves intubation success rates and reduces complications. ${ }^{13}$ Given that the average length of classroom training was reported as $4.3 \mathrm{~h}$, it is probable that some topics were unable to be covered due to a lack of time and resources.

Skill maintenance and intubation recertification varied among the respondents. Despite evidence that requiring a minimum number of procedures may not adequately evaluate intubation skills, $1278 \%$ of respondents indicated that RTs were automatically recertified if intubating a minimum number of patients each year, with only $11 \%$ required to pass a written test or undergo classroom training annually. Bishop et $\mathrm{al}^{14}$ described the evaluation and maintenance of RT intubation skills and found that the number of procedures performed was not correlated with successful skill demonstration in the OR, although a good score on a written exam was strongly correlated with successful skill demonstration. This study was too small (including only 11 RTs) to support any definitive conclusions..$^{14}$ It is possible that annual or biannual (similar to advanced life support classes) classroom education and simulation training along with a written test would improve staff skill retention, especially for staff who do not receive a large number of intubation opportunities or are gaining experience in intubation. Regardless of the methods, RTs should receive as much (if not more) training to maintain intubation skills as is received to acquire them. In a survey of pediatric emergency medicine medical directors, $62 \%$ felt that their physician staff did not have enough opportunities (mean 5.8 intubations/physician/y) to maintain their competence. ${ }^{15}$

Although the results should be interpreted cautiously due to the low number of responses, it appears as though intubation service was provided by RTs from larger institutions with a greater number of total hospital beds, ICU beds, and RTs. Thus, it is likely that intubation service by RTs is provided by facilities where there is a greater need for trained personnel to provide intubation. The 2 most common barriers cited by respondents from institutions where RTs do not intubate were that RTs have not traditionally intubated and there is no need for RTs to intubate. Interestingly, both groups were equally satisfied with their institution's intubation program. Resistance from providers was another barrier cited; this is likely to increase in the future as the role of mid-level providers increases in the critical care setting and competition for procedures increases. Lack of resources for training was also cited as a barrier; this is more challenging to overcome because the RT staff need to be available for training but also to work clinically. Training RTs requires resources and commitment from critical care physicians, emergency physicians, and anesthesia services, since training inexperienced staff has an impact on their daily practice. In particular, anesthesiologists may be reluctant to participate because train- 
ing RTs could result in an increase in time to incision and an increase in airway-related complications.

Attitudes about RT intubation practice differed with regard to whether RTs should be primary providers of intubation, despite similar attitudes about the safety of RTs intubating. It is likely that the differences were due to their personal experiences. In an unexpected finding, RTs from institutions where RTs do not intubate were more likely to think additional continuing education should be required for RTs who performed intubation. This may be due to their lack of experience in performing intubation in their institutions. Most respondents (78\%) felt their RTs were well trained to intubate, but a smaller percentage (62\%) felt that their program adequately evaluated their RTs' skills. This may be due to many respondents not formally evaluating RT skills annually but recertifying them based on the number of procedures performed each year. Given that only $57 \%$ of respondents engaged in quality assurance monitoring, it appears that many respondents are not evaluating individual staff performance annually.

This study has significant limitations. The low number of responses means that the results need to be interpreted cautiously and considered exploratory. Calculating a response rate was impossible because it was not possible to determine how many directors/managers are members of the AARConnect management section, and it was not possible for directors/managers who were not members of the AARConnect management section to be included. At this time, it is not possible to directly e-mail members of the section. As with all surveys, self-reporting bias is a possibility, and the self-selection of respondents is a significant limitation. The survey opens a window into intubation training practices among RTs, an important area where additional research is needed. As with most surveys, the nonrespondents may have had a significant effect on the results. Those who did respond may have a special interest in intubation practices, which may also have biased the results. Some questions may not have been worded clearly.

\section{Conclusions}

In this exploratory survey, intubation training for RTs varied among those surveyed. Simulation training and supervised intubations were the most common training methods. Recertification also varied, with most RTs being recertified if completing a minimum number of intubations.

\section{REFERENCES}

1. Mort TC. Complications of emergency tracheal intubation: immediate airway-related consequences: part II. J Intensive Care Med 2007; 22(4):208-215.

2. Sanders RC Jr, Giuliano JS Jr, Sullivan JE, Brown CA 3rd, Walls RM, Nadkarni V, et al. Level of trainee and tracheal intubation outcomes. Pediatrics 2013;131(3):e821-e828.

3. Stalhandske EJ, Bishop MJ, Bagian JP. Department of Veterans Affairs emergency airway management initiative. In: Henriksen K, Battles JB, Keyes MA, Grady ML, editors. Advances in patient safety: new directions and alternative approaches (Vol 1: Assessment). Rockville, Maryland: Agency for Healthcare Research and Quality; 2008:1-11.

4. Adams K, Scott R, Perkin RM, Langga L. Comparison of intubation skills between interfacility transport team members. Pediatr Emerg Care 2000;16(1):5-8.

5. Noblett KE, Meibalane R. Respiratory care practitioners as primary providers of neonatal intubation in a community hospital: an analysis. Respir Care 1995;40(10):1063-1067.

6. Thalman JJ, Rinaldo-Gallo S, MacIntyre NR. Analysis of an endotracheal intubation service provided by respiratory care practitioners. Respir Care 1993;38(5):469-473.

7. Zyla EL, Carlson J. Respiratory care practitioners as secondary providers of endotracheal intubation: one hospital's experience. Respir Care 1994;39(1):30-33.

8. Motulsky H. Intuitive biostatistics: a nonmathematical guide to statistical thinking. New York: Oxford University Press; 2010:32-33.

9. Joffe AM, Liew EC, Olivar H, Dagal AH, Grabinsky A, Hallman M, Treggiari MM. A national survey of airway management training in United States internal medicine-based critical care fellowship programs. Respir Care 2012;57(7):1084-1088.

10. Bernhard M, Mohr S, Weigand MA, Martin E, Walther A. Developing the skill of endotracheal intubation: implication for emergency medicine. Acta Anaesthesiol Scand 2012;56(2):164-171.

11. Kennedy CC, Cannon EK, Warner DO, Cook DA. Advanced airway management simulation training in medical education: a systematic review and meta-analysis. Crit Care Med 2014;42(1):169-178.

12. Mosier JM, Malo J, Sakles JC, Hypes CD, Natt B, Snyder L, et al. The impact of a comprehensive airway management training program for pulmonary and critical care medicine fellows: a three-year experience. Ann Am Thorac Soc 2015;12(4):539-548.

13. Losek JD, Olson LR, Dobson JV, Glaeser PW. Tracheal intubation practice and maintaining skill competency: survey of pediatric emergency department medical directors. Pediatr Emerg Care 2008;24(5): 294-299.

14. Bishop MJ, Michalowski P, Hussey JD, Massey L, Lakshminarayan S. Recertification of respiratory therapists' intubation skills one year after initial training: an analysis of skill retention and retraining. Respir Care 2001;46(3):234-237.

15. De Jong A, Molinari N, Conseil M, Coisel Y, Pouzeratte Y, Belafia $\mathrm{F}$, et al. Video laryngoscopy versus direct laryngoscopy for orotracheal intubation in the intensive care unit: a systematic review and meta-analysis. Intensive Care Med 2014;40(5):629-639.

This article is approved for Continuing Respiratory Care Education credit. For information and to obtain your CRCE

(free to AARC members) visit www.rcjournal.com

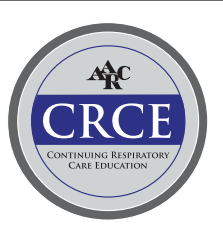

